\title{
Modelling Assessment on Causes of Road Accidents Along Kilimanjaro-Arusha Highway in Tanzania
}

\author{
Vicent Paul Nyakyi \\ Department of Wildlife Management, College of African Wildlife Management, Mweka, Tanzania \\ Email address: \\ vicenyakyi@gmail.com,vnyakyi@mwekawildlife.ac.tz \\ To cite this article: \\ Vicent Paul Nyakyi. Modelling Assessment on Causes of Road Accidents Along Kilimanjaro-Arusha Highway in Tanzania. Applied and \\ Computational Mathematics. Vol. 7, No. 2, 2018, pp. 71-74. doi: 10.11648/j.acm.20180702.15
}

Received: February 15, 2018; Accepted: March 20, 2018; Published: May 15, 2018

\begin{abstract}
This paper aims on assessing the risk factors which are associated to the cause of road accidents in KilimanjaroArusha highway $78.46 \mathrm{~km}$. Road accidents have been one of the paramount road cases in Tanzania. However, when ensuring road safety rules in Tanzania, it is important to assess the nature and causes of road accidents in the country. It is also necessary to find out the factors which lead to an obstacle of achieving road safety and regulations. This paper focuses on the assessment of road accidents in Tanzania and the associated factors such as inadequate road signs, inadequate carriageway width, lack of pedestrian facilities and law enforcement are considered to be critical shortcomings. The findings have shown the considerable proportions of accident and its outcomes of death and injuries at various black spot such as Kikavu River $60 \%$, Kikatiti $20 \%$, Nduruma bridge 10\%, Kilala slope 5\%, and Sadec 5\%. Also missing and poor road makings and road signs from CH: 0+200 $22+600$ needs to be rectified. In order to reduce road accidents in Kilimanjaro-Arusha section, the Government should rectify black spot areas by considering geometric standard in highway, set aside fund for provision and maintenance of traffic control devices, train road users on traffic laws and regulations, set aside fund for increasing road width with consideration of dual carriage way and climbing lane along mountain Kikavu area to reduce the action of overtaking. This study has revealed the pattern and trends of road accidents in Kilimanjaro-Arusha from 2013 to 2016. It shows that the accident occurrence was showing sign of decreasing from 2015 up to 2016. Passengers and pedestrians are the groups which identified to be always at highest risk of being injured or highly prone to motor traffic accidents. Driving under alcoholic behaviour (drugs, alcohol), distraction, over speed driving, overtaking, poor vehicle parking management and pedestrian fault are among of road user behaviour identified to cause accidents within the stretch.
\end{abstract}

Keywords: Road Accidents, Black Spot, Passengers and Pedestrians

\section{Introduction}

Road accidents are among major challenges facing our country. We see and hear about them every day in different parts of the country and some of them are catastrophic and cause serious damage to life and properties. Road accidents present health, social, economic and development challenges and they are listed among the leading causes of injuries, disabilities and deaths as it is the case with infectious diseases like malaria, TB, and HIV/AIDS. Road traffic accidents are the most frequent causes of injury-related deaths worldwide (Astrom et al., 2006). According to the World Report on Road Traffic Injury Prevention (2004), traffic accidents account for about 3000 daily fatalities worldwide. Pierce and Maunder (1998), under the auspices of
Road Research Laboratory in UK, found out that road accidents worldwide are estimated to a total of $20,000,000$ victims for a time period, of which $70 \%$ occurred in developing countries due to the low income allocated to the implementation of road safety measures. Akinlade (2000), while looking at the same subject matter from the public health point of view, noted that, road traffic accidents have been recognized as a serious health problem in both developed and developing countries. He observed that road traffic accidents have been increasing in developing countries like Nigeria and Tanzania while there is a noted decrease of road accidents in developed countries like Australia. The increase in road traffic has been followed by a sudden increase in the road accident. Death, injuries and property loss with severe financial and social implications on those 
involved from traffic accidents are causes of great concern throughout the world, the traffic accidents can never totally be eliminated but can be minimized through suitable traffic engineering and traffic management counter measures somehow the traffic accidents can be reduced. (PIARC road safety manual, 2007)

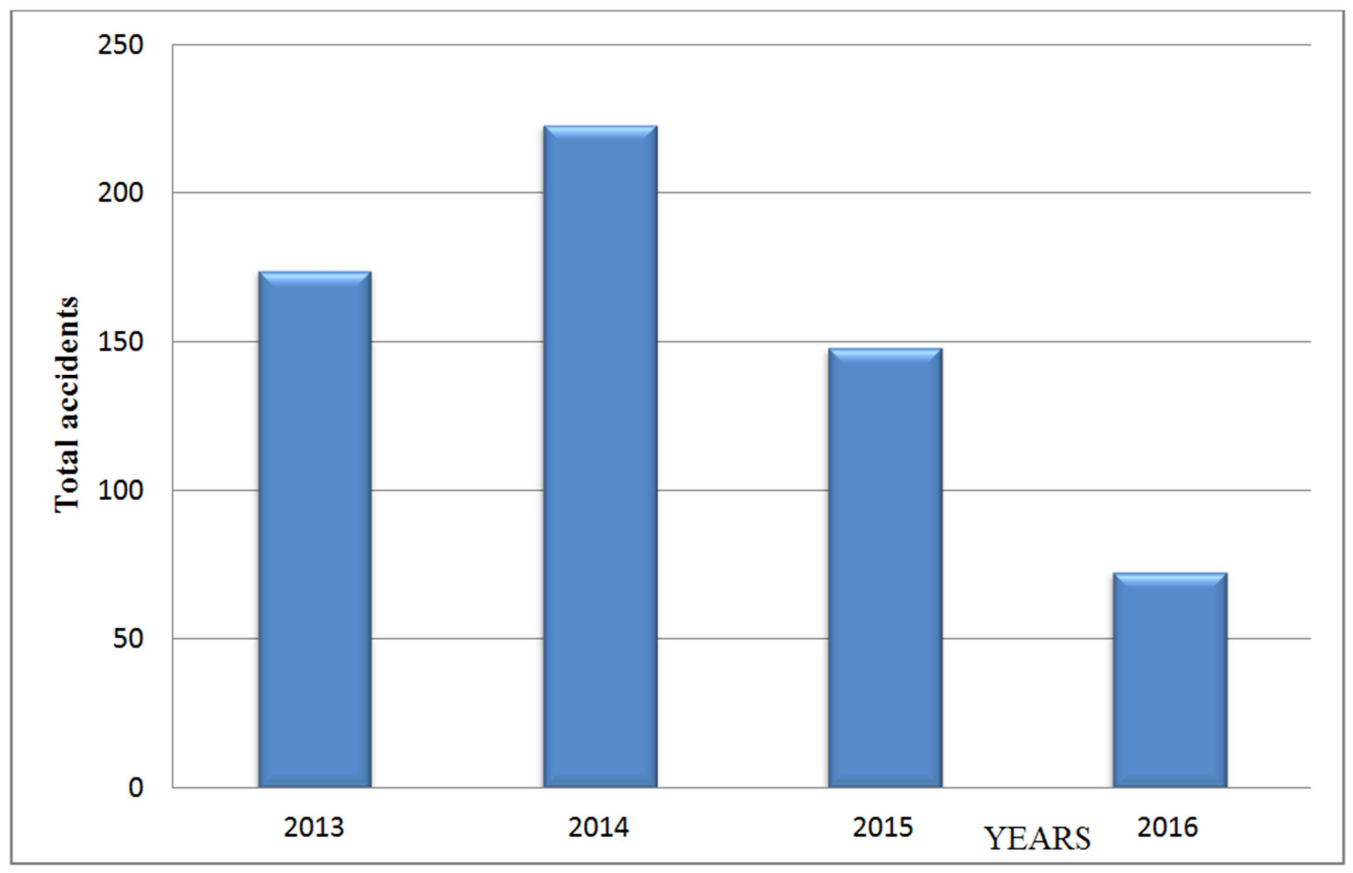

Figure 1. Accident trends In Kilimanjaro-Arusha Highway.

The National Road Safety Council of Tanzania in 2010 reported that the problem of road traffic accidents was on the increase for the last five years. This problem has not only caused loss of peoples' lives, but also leaves behind devastated families, untold misery to the respective families, loss of income to the nation and caused permanent disabilities to accident victims. This paper aims to formulate model for assessment of causes of road accidents along Kilimanjaro-Arusha highway.

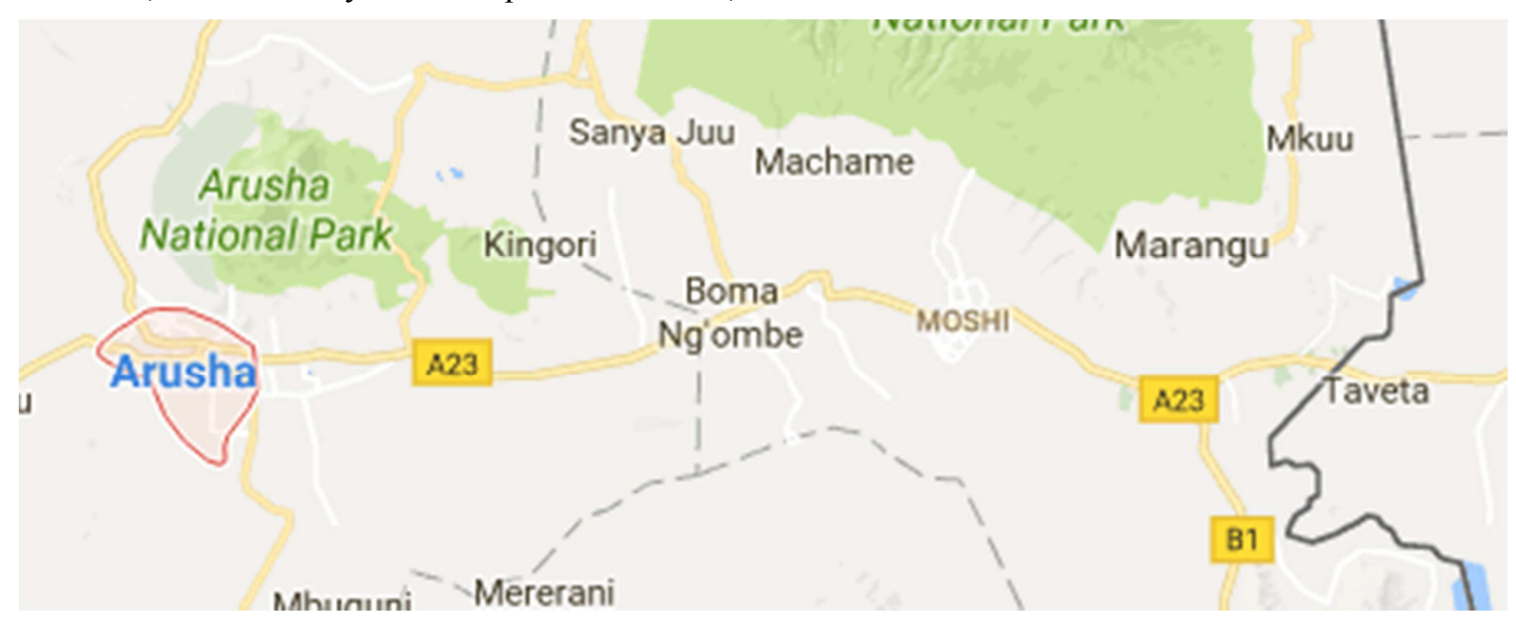

Figure 2. Location of the Kilimanjaro-Arusha high way.

\section{Observation from Literatures}

Generally, the literature agrees that, road accident is a severe problem; and in order to solve it one should consider multiple factors that are key causes of the road accidents for effective establishment of countermeasures to solve the problem. Studies have been developed to assess road accidents by considering several factors most of them being age, driving behavior and junction type. However, none of these studies have considered mathematically the factor of inadequate road signs, inadequate carriageway width, lack of pedestrian facility and law enforcement. Therefore, this justifies the importance of developing the model that assess road accidents in Tanzania by considering four factors which are inadequate road signs, inadequate carriageway width, lack of pedestrian facility and law enforcement for the aim of coming up with the suggestion that will yield effective solution for the problem. 


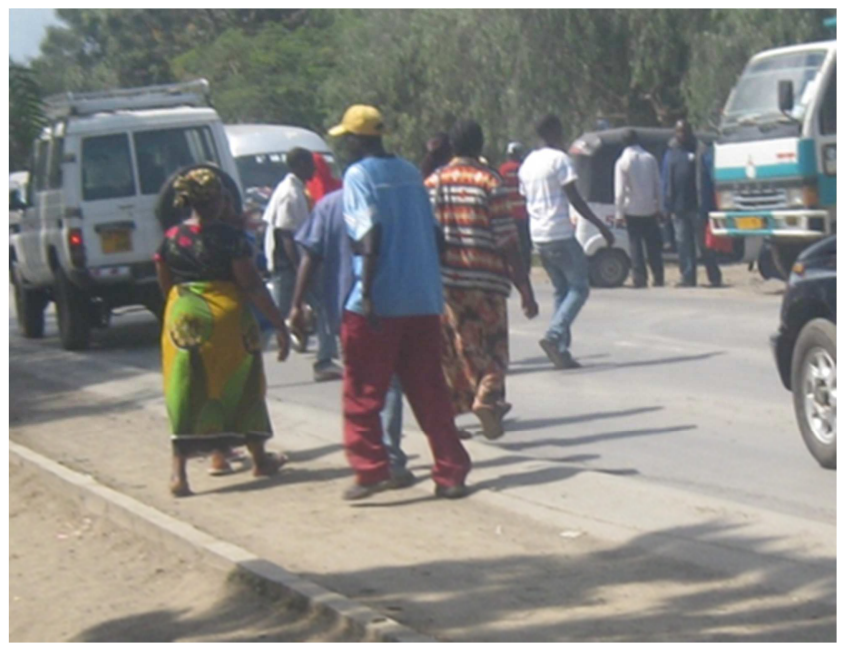

Figure 3. People crossing the road with their own convenience, no zebra crossing.

\section{Design and Methods}

The research methodology was divided into four stages which included both quantitative and qualitative

approaches. The first stage was the feasibility study, where surveying approach with detailed on-site observation was conducted in order to investigate the existing relationship between road accidents caused inadequate road signs, inadequate carriageway width, lack of pedestrian facility and law enforcement and its impact to the society. The second stage was the objective formulation, the third stage dealt with data collection, and the last stage was the validation of the model.

\subsection{Model Development}

The model was formulated from the data obtained from Kilimanjaro and Arusha regions and analyzed. The following techniques were used; consultative meeting, field survey and other data obtained from government organizations such as Traffic police and Tanzania National Roads Agency (TANROADs).

\subsection{The Kind of Data Collected Includes}

The data which were used to show the number of accidents recorded along the stretch. This data were obtained from Kilimanjaro and Arusha regional Traffic police offices. These data show place at which the accident occurred, date of accident, time of accident, type of vehicle involved, type of road users involved in accident whether a pedestrians or passengers, deaths and injuries at site of accident, a review of records was done systematically and all records were manually sorted out starting from 2013 to 2016. In analysis these data will help to find area with high distribution of accidents, determine which group of road users is much affected by road accidents within the stretch.

Table 1. Accident records (2013-2016).

\begin{tabular}{lllll}
\hline BLACK SPOT & \multicolumn{2}{l}{ YEARS } & & \\
\cline { 2 - 5 } LOCATION & $\mathbf{2 0 1 3}$ & $\mathbf{2 0 1 4}$ & $\mathbf{2 0 1 5}$ & $\mathbf{2 0 1 6}$ \\
\hline Kikavu River & 32 & 53 & 51 & 35 \\
Kikatiti & 24 & 40 & 12 & 4 \\
Nduruma bridge & 66 & 38 & 34 & 5 \\
Kilala Slope & 26 & 63 & 11 & 14 \\
Sadec & 27 & 31 & 32 & 17 \\
Total & 175 & 225 & 140 & 75 \\
\hline
\end{tabular}

\section{Model Formulation and Mathematical Analysis}

The models were developed using Statistical Package for Social Science (SPSS) software program from the data collected in Kilimanjaro and Arusha regions. The used variables in the models with their corresponding descriptions were as in Table 2.

Table 2. Variables and their Description.

\begin{tabular}{ll}
\hline Variable & Description \\
\hline $\mathrm{Y}_{0}$ & Inadequate road signs \\
$\mathrm{Y}_{1}$ & Inadequate Carriage way width \\
$\mathrm{Y}_{2}$ & Lack of Pedestrian facility \\
$\mathrm{Y}_{3}$ & Law enforcement \\
\hline
\end{tabular}

\subsection{Mathematical Analysis}

As most of the data in this work were obtained from traffic police offices, TANROADs and motor drivers we have assumed that some of the road accidents are not reported. From this assumption, the work with the data used can lack exactness with precision due to the way they are needed to be presented. Therefore, we consider them as approximated data which can give us a full overview of road accidents in Tanzania. Since the data collected can be analyzed by multiple linear method the SPSS software program was used to formulate the multiple linear equations as described in equation 1 . The multiple linear regression models were used to analyze multivariate data as reported by Fajaruddin et al. (2011) and Ezequal (2013).

\subsection{Mathematical Model}

The SPSS software program was mainly used to describe the data by formulating the models depending on the type of data entered. With reference to the collected data, one model are presented as in equations 1 for Kilimajaro-Arusha high way. A similar approach of model formulation has been used in road accidents as reported by Akhigbe (2010) and Nyakyi et al (2014). 


\subsection{Analysis of Road Accidents in Kilimajaro-Arusha High Way}

Table 3. Coefficients for road accidents and contributing factors in Kilimanjaro-Arusha high way.

\begin{tabular}{|c|c|c|c|c|c|c|}
\hline \multicolumn{7}{|c|}{ Coefficients $^{\mathrm{a}}$ for Kilimanjaro-Arusha high way } \\
\hline \multirow{2}{*}{\multicolumn{2}{|c|}{ Model }} & \multicolumn{2}{|c|}{ Unstandardized Coefficients } & \multirow{2}{*}{$\begin{array}{l}\text { Standardized Coefficients } \\
\text { Beta }\end{array}$} & \multirow{2}{*}{$\mathbf{t}$} & \multirow{2}{*}{ Sig } \\
\hline & & B & Std. Error & & & \\
\hline \multirow{5}{*}{1} & (Constant) & 281.022 & .000 & & . & . \\
\hline & Lack of Pedestrian facilityY ${ }_{2}$ & -0.13 & .000 & .100 & . & . \\
\hline & Inadequate Carriage way width $\mathrm{Y}_{1}$ & 4.513 & .000 & .326 & . & . \\
\hline & Inadequate road signs $Y_{o}$ & 6.838 & .000 & -.825 & . & . \\
\hline & Law enforcement $Y_{3}$ & -2.198 & .000 & 1.618 & . & . \\
\hline
\end{tabular}

a. Dependent Variable: Number of accident

From Table 3, the formulated model for KilimanjaroArusha was presented as equation 1:

$$
\mu-281.022=6.838 Y_{O}+4.513 Y_{1}-0.13 Y_{2}-2.198 Y_{3}
$$

\subsection{Effect of Individual Variable in the Model}

When we consider all factors (Inadequate road signs, Inadequate Carriage way width, lack of Pedestrian facility and law enforcement) as zero, the number of road accidents in Kilimanjaro-Arusha high way will be constant of about 281 accidents.

For variable $\mathrm{Y}_{0}$ (Inadequate road signs), holding fixed the number of Inadequate carriage way width, lack of Pedestrian facility and law enforcement then as the number of Inadequate road signs is increased by one unit, the number of road accidents will be increased by 6.838 units.

For variable $\mathrm{Y}_{1}$ (Inadequate Carriage way width), holding fixed the number of Inadequate road signs, lack of Pedestrian facility and law enforcement if the number of Inadequate Carriage way width increased by one unit, the number of road accidents will increase by 4.513 units.

For variable $\mathrm{Y}_{2}$ (Lack of Pedestrian facility), when holding fixed the number of Inadequate road signs, Inadequate carriage way width and law enforcement if the number of Lack of Pedestrian facility increased by one unit, the number of road accidents will be decrease by 0.13 units.

For variable $\mathrm{Y}_{3}$ (Law enforcement), holding fixed the number of Inadequate road signs, Inadequate carriage way width and Lack of pedestrian facility then if the number of Law enforcement is increased by one unit, the number of road accidents will decrease by -2.198 units.

\section{Recommendation and Conclusion}

\subsection{Conclusion}

The formulated model has shown a strong relationship between inadequate road signs, inadequate carriageway width, lack of pedestrian facility and law enforcement. These factors contribute to road accidents as shown in Table 3 as well as the formulated model.

\subsection{Recommendation}

From this observation, it can be seen that, the formulated model can be used by the ministry of infrastructure to construct good roads in order to reduce the rate of accidents. The government must enforce and implement strong road safety rules and high punishment should be given to those who break the law. Government should implement strong laws against corruption especially to those who are concerning with the implementation traffic regulations.

\section{References}

[1] Akinlade, C. (2000). Knowledge, Attitudes, and Practices of Road Safety and First Aid among Commercial Motorcyclists in the. Nigeria: An unpublished dissertation for the award of Master of Public Health/Health Education.

[2] Akhigbe, P. (2010). Motor cycle Related Maxillofacial injures. Urbarn areas in Nigeria: Umea International School of Public Health.

[3] Astrom, J. S. (2006). Signatures of Four Generations of Road Safety Planning. Journal of Eastern African Research and Development, Vol. 120, pp. 186-201.

[4] Ezequal U. (2013) Multiple Linear Regression Estimation and Properties. Universidade Valencia: version: 09-2013.

[5] Fajaruddin M, and Motohiro F. (2011). Development of Accident Predictive Model for RuralRoadway. World Academy of Science, pp 126-131.

[6] MATLAB Statistics Toolbox User's Guide, The Math Works, 2012.

[7] Nyakyi, V., Kuznetsov, D. and Nkansah-Gyekye, Y. (2014). Mathematical Model to Assess Motorcycle Accidents in Tanzania. Journal of Mathematical Theory and Modeling. Vol. 4, No. 9, 112-119.

[8] PLARC Road Safety Manual, 2007World Report on Road Traffic Injury Prevention, 2004. 